NBER WORKING PAPER SERIES

\title{
THE IMPACT OF MEDICAID ON LABOR FORCE ACTIVITY AND PROGRAM PARTICIPATION: EVIDENCE FROM THE OREGON HEALTH INSURANCE EXPERIMENT
}

\author{
Katherine Baicker \\ Amy Finkelstein \\ Jae Song \\ Sarah Taubman \\ Working Paper 19547 \\ http://www.nber.org/papers/w19547 \\ NATIONAL BUREAU OF ECONOMIC RESEARCH \\ 1050 Massachusetts Avenue \\ Cambridge, MA 02138 \\ October 2013
}

The authors are grateful to Gerald Ray and David Foster for their help and support; and to the Oregon Health Authority and the Division of Medical Assistance Programs for invaluable continuing cooperation in the fielding of the Oregon Health Insurance Experiment. We are also grateful to Josh Angrist, Manasi Deshpande, Tal Gross, Guido Imbens, Larry Katz, Matt Notowidigdo, and Ben Olken, for helpful comments and advice and to Allyson Barnett, Mira Bernstein, and Annetta Zhou for extraordinary research assistance. We gratefully acknowledge funding from the Assistant Secretary for Planning and Evaluation in the Department of Health and Human Services, the California HealthCare Foundation, the John D. and Catherine T. MacArthur Foundation, the National Institute on Aging (P30AG012810, RC2AGO36631 and R01AG0345151), the Robert Wood Johnson Foundation, the Sloan Foundation, the Smith Richardson Foundation, and the U.S. Social Security Administration (through grant 5 RRC 08098400-03-00 to the National Bureau of Economic Research as part of the SSA Retirement Research Consortium). We also gratefully acknowledge Centers for Medicare and Medicaid Services' matching funds for this evaluation. The findings and conclusions expressed are solely those of the author(s) and do not represent the views of SSA, the National Institute on Aging, the National Institutes of Health, any agency of the Federal Government, any of our funders, or the NBER.

At least one co-author has disclosed a financial relationship of potential relevance for this research. Further information is available online at http://www.nber.org/papers/w19547.ack

NBER working papers are circulated for discussion and comment purposes. They have not been peerreviewed or been subject to the review by the NBER Board of Directors that accompanies official NBER publications.

(C) 2013 by Katherine Baicker, Amy Finkelstein, Jae Song, and Sarah Taubman. All rights reserved. Short sections of text, not to exceed two paragraphs, may be quoted without explicit permission provided that full credit, including $(\mathcal{C}$ notice, is given to the source. 
The Impact of Medicaid on Labor Force Activity and Program Participation: Evidence from the Oregon Health Insurance Experiment

Katherine Baicker, Amy Finkelstein, Jae Song, and Sarah Taubman

NBER Working Paper No. 19547

October 2013, Revised November 2013

JEL No. H51,H53,I13,J20

\title{
ABSTRACT
}

In 2008, a group of uninsured low-income adults in Oregon was selected by lottery for the chance to apply for Medicaid. We use this randomized design and 2009 administrative data to evaluate the effect of Medicaid on labor market outcomes and participation in other social safety net programs. We find no significant effect of Medicaid on employment or earnings: our 95 percent confidence intervals allow us to reject that Medicaid causes a decline in employment of more than 4.4 percentage points, or an increase of more than 1.2 percentage points. We find that Medicaid increases receipt of food stamps, but has little, if any, impact on receipt of other government benefits, including SSDI.

\author{
Katherine Baicker \\ Professor of Health Economics \\ Jae Song \\ Department of Health Policy and Management \\ Harvard School of Public Health \\ 677 Huntington Avenue \\ Social Security Administration \\ Boston, MA 02115 \\ and NBER \\ kbaicker@hsph.harvard.edu \\ Office of Quality Performance \\ 2121 Crystal Drive, Suite 825 \\ Arlington, VA 22202 \\ jae.song@ssa.gov \\ Sarah Taubman \\ National Bureau of Economic Research \\ Amy Finkelstein \\ Department of Economics, E17-228 \\ 1050 Massachusetts Ave \\ Cambridge, MA 02138 \\ MIT \\ staub@nber.org \\ 77 Massachusetts Avenue \\ Cambridge, MA 02139 \\ and NBER \\ afink@mit.edu
}

An online appendix is available at:

http://www.nber.org/data-appendix/w19547 
Most analyses of the impact of expanding Medicaid focus on the direct costs of the program from increased health expenditures and the direct benefits from improved health and reduced exposure to medical expenditure risk. In this paper, we consider possible additional impacts of Medicaid on enrollees' labor market activity and take-up of government benefits such as disability insurance and welfare. As states face choices about expanding their Medicaid programs, these indirect effects could create important additional costs and benefits. A priori, however, the sign, let alone the magnitude, of the effects of Medicaid on labor force and program participation is unclear.

There are a number of potential channels through which Medicaid coverage could increase employment and decrease participation in other government programs. For example, by improving health or reducing disruptive health emergencies, Medicaid coverage could increase employment, hours worked, wages, and earnings. Higher earnings could in turn reduce receipt of benefits from social safety net programs, particularly those that are means-tested. There are also non-earnings channels through which Medicaid could decrease participation in other public programs. Improved health could reduce eligibility for disability-based programs. Public health insurance coverage might reduce the benefit from (and hence participation in) other programs that provide access to public health insurance (such as various disability programs). Some thus hope that expanding Medicaid will raise incomes, increase government income tax revenues, and reduce government spending on other programs. ${ }^{1}$

However, it is also possible for Medicaid to reduce labor force activity and/or increase participation in other public programs. The income ceiling for Medicaid eligibility may

\footnotetext{
${ }^{1}$ For example, the National Health Care for the Homeless Council argues that Medicaid expansion can break "a downward spiral: illness results in loss of employment - an in turn, income, housing, and health coverage ... Medicaid can break this cycle" (2013).
} 
discourage employment and earnings, and the insurance coverage itself may reduce the motivation to seek employment to get health insurance. Any decrease in earnings could in turn increase eligibility for, and hence participation in, other means-tested programs. In addition, participation in one government benefit program (Medicaid) may increase participation in others by increasing awareness of the programs or by reducing the transaction costs of applying (e.g. Yelowitz (1996), McConnell (1991)). Such channels have fueled concern that expanding Medicaid would reduce earnings and tax revenues and further raise government spending. ${ }^{2}$

There is limited evidence available to gauge which effects dominate. Isolating the causal effect of Medicaid is challenging; individuals who are eligible for and choose to enroll in Medicaid likely differ from others in their labor supply and propensity to enroll in other public programs, and such differences are difficult to control for in observational studies. A set of circumstances in Oregon, however, provides an opportunity to evaluate the causal effects of Medicaid expansions on these outcomes using a randomized controlled design.

In 2008, Oregon initiated a limited expansion of its Medicaid program for low-income, uninsured adults, drawing approximately 30,000 names by lottery from a waiting list of 90,000. Those selected won the chance to apply for Medicaid and to be covered if they met eligibility requirements. The lottery increased enrollment in Medicaid by about 25 percentage points, while not reducing rates of coverage by private insurance (Finkelstein et al., 2012).

We use the lottery to conduct what is to our knowledge the first randomized evaluation of the impact of expanding Medicaid on labor supply and participation in safety net programs, specifically cash welfare (TANF; cash assistance to low-income families with dependent children), food stamps (SNAP; financial assistance for food purchases for low-income

${ }^{2}$ For example, the Heritage Foundation argues "Medicaid expansion actually locks low-income workers in poverty because of its backward incentives that discourage work" (Segner, 2013). 
individuals and families), Supplemental Security Income, and Social Security Disability

Insurance (SSI and SSDI; supplemental income to disabled individuals and their families). ${ }^{3}$

These are most of the major social insurance and transfer programs relevant for our population, with the important exceptions of unemployment assistance and the Earned Income Tax Credit.

We do not expect to see effects on TANF or SSI, since eligibility for these programs would have already conferred Medicaid eligibility independent of the lottery (Office for Oregon Health Policy and Research, 2009). Using 2009 administrative data, we find that Medicaid has little if any impact on labor market outcomes or receipt of cash welfare or disability insurance, but increases receipt of food stamps. ${ }^{4}$

I. Background. Oregon's lottery allocated spots in its Medicaid expansion program for lowincome adults who were not categorically eligible for the state's traditional Medicaid program. Individuals in households randomly selected by the lottery could enroll in Medicaid if they completed the application process and met eligibility criteria, including being: ages 19-64; not otherwise eligible for Medicaid or other public health insurance; Oregon residents; U.S. citizens or legal immigrants; uninsured for six months; with income below the federal poverty level and assets below $\$ 2,000$. The Medicaid program provides relatively comprehensive medical benefits with no consumer cost sharing and low or no monthly premiums. The lottery process and the Medicaid program are described in more detail elsewhere (Finkelstein et al. 2012).

Prior work on the Oregon Health Insurance Experiment has examined the impacts of Medicaid coverage in the first two years after the lottery, using hospital discharge records, credit

\footnotetext{
${ }^{3}$ SSDI pays if the beneficiary has worked long enough and paid Social Security taxes, and SSI pays benefits based on financial need; both confer eligibility for public health insurance (Medicare and Medicaid respectively).

${ }^{4}$ An on-line appendix provides considerably more detail on our data and methods; it also presents all results discussed but not shown here, as well as additional results not discussed here.
} 
reports, mail surveys, and in-person interviews and physical exams. We found that Medicaid increased health care use - including outpatient visits, prescription drugs, and hospital visits - as well as the use of preventive care, and diagnosis of and medication for some specific conditions. Medicaid decreased financial strain, such as the probability of having catastrophic out-of-pocket medical expenditures or unpaid medical bills sent to collection agencies. Medicaid increased self-reported general health and reduced the probability of screening positive for depression. We did not find statistically significant effects on measured blood pressure, cholesterol, or glycated hemoglobin levels (diabetic blood sugar control). In the case of diabetes, our confidence intervals are too large to rule out the decline in blood sugar that we would expect based on our estimated effect on diabetes medication and the clinical trial literature on the impact of that medication on blood sugar; in other cases, such as hypertension, we can reject declines of the magnitude found in prior quasi-experimental studies of Medicaid. More information about the study design and results can be found in Finkelstein et al., 2012, Baicker et al., 2013, and on the study website www.nber.org/oregon.

II. Data and Methods. All the analyses reported in the main text were pre-specified and publicly archived on January 22, 2013 at hypotheses@ povertyactionlab.org. Pre-specification was designed to minimize issues of data and specification mining and to provide a record of the full set of planned analyses.

We use 2009 administrative data to study the impact of Medicaid in the year following the 2008 lottery. We use data from the Social Security Administration (SSA) on annual earnings and receipt of SSDI and SSI, as well as state administrative records on receipt of SNAP and TANF benefits. State administrative records are also used to measure Medicaid coverage. 
We matched our lottery list data to SSA's records using name and date of birth from the lottery sign up. We were able to match about $85 \%$ of the approximately 75,000 individuals in the lottery analytic sample to the SSA records; match rates were balanced between treatment and control. The state matched lottery participants to their SNAP and TANF records; we limit our analysis of these outcomes to the sub-sample that we also matched to the SSA data.

We estimate intent-to-treat (ITT) models comparing outcomes among those selected in the lottery (the treatment group) to those who were on the list but not selected (the controls) by fitting the following OLS equation:

$$
y_{i h}=\beta_{0}+\beta_{1} \operatorname{LOTTERY}_{h}+X_{i h} \beta_{2}+\varepsilon_{i h}
$$

where $i$ denotes an individual and $h$ denotes a household. LOTTERY is an indicator variable for whether or not household $h$ was selected by the lottery. We control for a set of indicators for the number of household members on the lottery list because selection was random conditional on the number of listed household members (Finkelstein et al., 2012). We also control for the prerandomized (measured in the year 2007) version of the outcome $y_{i h}$; our results are not sensitive to excluding this control or adding additional pre-randomization demographic covariates. All standard errors are clustered by household to account for intra-household correlation.

The coefficient on LOTTERY $\left(\beta_{1}\right)$ gives the average difference in (adjusted) means between the treatment group (the lottery winners) and the control group (those not selected by the lottery); it gives the impact of being able to apply for Medicaid through the Oregon lottery. We are also interested in the impact of being covered by Medicaid. We model this as follows:

$$
y_{i h}=\pi_{0}+\pi_{1} M E D I C A I D_{i h}+X_{i h} \pi_{2}+v_{i h}
$$

where MEDICAID is an indicator variable for having ever been covered by Medicaid during our 
study period (March 102008 through December 31, 2009) and all other variables are defined in equation (1). We estimate equation (2) by two stage least squares using the following first stage equation:

$$
\text { MEDICAID }{ }_{i h}=\delta_{0}+\delta_{1} \text { LOTTERY }_{i h}+X_{i h} \delta_{2}+\mu_{i h}
$$

in which the excluded instrument is the variable LOTTERY. We interpret the coefficient on MEDICAID from IV estimation of equation (2) as a local average treatment effect of insurance (LATE) for the compliers (i.e. the subset of individuals who obtain Medicaid on winning the lottery and who would not without winning the lottery). The first stage impact of winning the lottery on Medicaid coverage is about 0.25 , with an F-stat above 4,500. The first stage coefficient is considerably less than 1 because only about 60 percent of individuals who won the lottery sent back applications, and only about half of those who returned applications met the eligibility requirements (Finkelstein et al., 2012). The LATE estimates require the additional assumption that the only effect of winning the lottery on the outcomes studied is through its effect on insurance coverage. This may not be strictly true when it comes to receipt of SNAP and TANF benefits that can be applied for at the same office where one submits a Medicaid application; we discuss this in more detail below.

III. Results: Labor Market Activities. Table 1 summarizes our main labor market findings. It shows the impact of Medicaid on (1) whether the individual had any earnings (i.e. employment), (2) the amount of individual earnings, and (3) whether individual earnings are above the federal poverty level (FPL). ${ }^{5}$ We find no statistically significant impact of Medicaid on any of these measures of 2009 labor market activity. This is consistent with earlier findings on self-reported

\footnotetext{
${ }^{5}$ We view the FPL as an interesting cut of the data (do the individuals earn enough to raise their households out of poverty?). However as described in more detail in the appendix, error in our ability to measure the individual's household structure means there will be a fair bit of noise in our cut point.
} 
hours of work (Finkelstein et al. 2012, appendix). Our (statistically insignificant) point estimates indicate that Medicaid causes a decline in employment of 1.6 percentage points (or about 3\%, relative to the control group). Our 95 percent confidence interval allows us to reject a decline in employment of more than 4.4 percentage points or an increase of more than 1.2 percentage points. We find a (statistically insignificant) decline in mean annual earnings of $\$ 195$ (or about $3 \%$, relative to the control group); our 95 percent confidence interval allows us to reject a decline in mean earnings of more than $\$ 762$ or an increase of more than $\$ 372$.

Most of the prior, quasi-experimental literature on the impact of Medicaid on labor market activities focuses on a time in which Medicaid eligibility was linked (or being de-linked) from participation in cash welfare. Gruber and Madrian's (2004) review of this literature concludes that there is little if any impact of Medicaid coverage on labor supply. Two recent papers, however, focus on the impact of Medicaid on employment in the absence of such linkages and find evidence that Medicaid decreases employment for pregnant women (Dave et al. 2013) and childless adults (Garthwaite et al., 2013). For example, Garthwaite et al. estimate that a Medicaid eligibility restriction that reduced enrollment among childless adults by about 10 percent increased employment by 4.6 percentage points, suggesting that among those losing coverage, employment increased by almost 50 percentage points - an estimate well outside our own 95 percent confidence interval.

These other papers suggest that the decline in employment associated with Medicaid coverage is related to the substantial Medicaid crowd-out of private insurance that they estimate in their population. By contrast, in our setting, we find no statistically or economically significant impact of Medicaid coverage on private health insurance (Finkelstein et al. 2012), suggesting that for the compliers in our experiment, private insurance through an employer is not 
an option. This lack of crowd-out may reflect the relatively low (100\% of FPL) income eligibility criteria for our lotteried Medicaid program; by contrast, the Tennessee Medicaid expansion program studied by Garthwaite et al. had no income ceiling, and about $40 \%$ of those covered had income above the FPL, with about one-fifth of those having income above $200 \%$ of the FPL. The lack of crowd-out in our setting may also reflect enforcement of the eligibility criterion requiring those selected to have been without health insurance for six months (although it is unclear how rigorously this was enforced).

IV. Results: Participation in Other Public Programs. Table 2 shows the impact of Medicaid on participation in the four public programs we measured. The main effect is on food stamps (SNAP), which is by far the most commonly used of the programs studied with nearly 60 percent of the control group receiving SNAP benefits. The reduced form indicates that winning the lottery increases the probability of receiving food stamps by a statistically significant 2.5 percentage points (4\%, relative to the control mean). It increases (unconditional) annual household food stamp benefits by a statistically significant $\$ 73$; this is equivalent to a $\$ 3000$ increase in annual benefits for those who newly receive benefits, assuming that (as seems likely given the formula for SNAP benefits) all of the increase in benefits occurs through the participation margin. Naturally, the IV estimates of the impact of Medicaid coverage are about 4 times larger, suggesting that Medicaid increases the probability of SNAP receipt by about 10 percentage points (about $15 \%$ ).

The IV results for SNAP need to be interpreted with some caution. Winning the lottery might have a direct effect on SNAP receipt, regardless of whether winning affects Medicaid coverage: if an individual applies for Medicaid in Oregon in person (rather than by mail), case 
workers are instructed to offer assistance to interested applicants in applying for TANF and

SNAP as well. As an indirect way of gauging the extent to which the increase in SNAP stems

from this "application" effect independent of coverage, we investigated the timing of the increase in SNAP relative to winning the lottery. ${ }^{6}$ The probability of becoming newly covered by SNAP increases in the first three months of winning the lottery but also continues to increase in subsequent three month increments for the whole time period we examine (out to 12-15 months post lottery winning). This suggests that while there may be a direct application effect, there are also longer-run effects likely attributable to Medicaid coverage itself. Since we do not find an impact of Medicaid coverage on earnings, the increase in SNAP due to Medicaid presumably reflects an effect of Medicaid coverage on increased awareness of other government programs.

There is not much evidence of any impact on receipt of the other government benefits studied. We find some evidence of an increase in the probability of receipt of TANF, but caution that this result is not only economically quite small, but is also less robust than the SNAP estimates. ${ }^{7}$ We find no statistically significant effect on SSDI or SSI benefit receipt. ${ }^{8}$ Combining information on benefit amounts in each of these four programs with the previous earnings results, we find no evidence of a statistically significant impact of Medicaid on measured income.

\footnotetext{
${ }^{6}$ Conversations with state officials in Oregon indicate receipt of SNAP benefits is retroactive to the application date. Since individuals who won the lottery were sent applications about a month after the notification date, and then had 45 days to apply for Medicaid, presumably any immediate effect from applying would show up as SNAP receipt within the first three months.

${ }^{7}$ We do not find statistically significant increases in in receipt or amount of TANF benefits when analyzed for a slightly different population and time frame; by contrast, the statistically significant increases in receipt of and amount of SNAP benefits is robust to the slightly different analysis sample (Finkelstein et al. (2012)).

${ }^{8}$ Benefit receipt is recorded retrospectively based on the date the individual became eligible for the program following a successful application process; data are current as of the end of 2012. However, in part because of concerns about lags between applications and approvals, we also (post-hoc) examined the impact on SSDI and SSI applications and approvals using SSA's 831 files. We found some suggestive evidence of statistical effect on SSDI and SSI applications, but not one that was economically meaningful (e.g. Medicaid coverage may cause about a 1 percentage point increase in applications to each program, and perhaps a half a percentage point increase in approvals for SSDI).
} 
This pattern of results is consistent with hypothesized information or woodwork effects on program participation, concentrated in a program administered by the same caseworkers and where, unlike SSI and TANF (that should have conferred Medicaid eligibility outside of the lottery), we expected to see a greater effect. There has been relatively little prior work on the impact of Medicaid on participation in other government programs. Most of the studies we know of focused on the consequences of severing a statutory link between participation in a given program and Medicaid eligibility, which is a somewhat different mechanism than what we are examining here. ${ }^{9}$

V. Conclusion. Using a randomized controlled design, we find no effect of Medicaid on employment or earnings. Our 95 percent confidence intervals allow us to reject that Medicaid causes a decline in employment of more than 4.4 percentage points, or an increase of more than 1.2 percentage points. We find that Medicaid increases the probability of receiving food stamps, but has no economically and statistically significant effect on receipt of TANF, SSI, or SSDI.

\footnotetext{
${ }^{9}$ There is evidence that de-coupling Medicaid eligibility from participation in SSI reduced participation in SSI (Yelowitz 2000); it is not clear whether de-coupling Medicaid eligibility from the receipt of cash welfare reduces enrollment in cash welfare (compare Yelowitz 1995 and Ham and Shore-Sheppard 2005).
} 


\section{REFERENCES}

Baicker, Katherine, Sarah Taubman, Heidi Allen, Mira Bernstein, Jonathan Gruber, Joseph Newhouse, Eric Schneider, Bill Wright, Alan Zaslavsky, Amy Finkelstein, and the Oregon Health Study Group. 2013. New England Journal of Medicine 368 (1713-1722).

Dave, Dhaval, Sandra Decker, Robert Kaestner, Kosali Simon. 2013. "The Effect of Medicaid Expansions in the Late 1980s and Early 1990s on the Labor Supply of Pregnant Women." NBER Working Paper 19161.

Finkelstein, Amy, Sarah Taubman, Bill Wright, Mira Bernstein, Jonathan Gruber, Joseph Newhouse, Heidi Allen, Katherine Baicker, and the Oregon Health Study Group. 2012. "The Oregon Health Insurance Experiment: Evidence from the First Year." Quarterly Journal of Economics 127(1057-1106).

Garthwaite, Craig, Tal Gross and Matthew J. Notowidigdo. 2013. "Public Health Insurance, Labor Supply, and Employment Lock.” NBER Working Paper 19220

Gruber, Jonathan and Brigitte C. Madrian. 2004. "Health Insurance, Labor Supply, and Job Mobility: A Critical Review of the Literature." in Health Policy and the Uninsured (McLaughlin, Catherine, ed.) Washington, D.C.: Urban Institute Press.

Ham, John and Lara Shore-Sheppard. 2005. "Did Expanding Medicaid Affect Welfare Participation" Industrial and Labor Relations Review 58(3).

McConnell, S. 1991. "The Increase in Food Stamp Participation between 1989 and 1990.” Report to Congress, submitted by Mathematica.

National Health Care for the Homeless Council. "Medicaid Expansion: Improving Health and Stability, Reducing Costs \& Homelessness." 2013. www.nhchc.org/wp.../NHCHC-MedicaidExpansion-Position-Paper.pdf

Office for Oregon Health Policy and Research, "Trends in Oregon's HealthCare Market and the Oregon Health Plan: A Report to the 75th Legislative Assembly," (February 2009).

Senger A. "10 Myths About the Obamacare Medicaid Expansion." The Foundry: Conservative Policy News Blog from The Heritage Foundation. 2013 April

24. http://blog.heritage.org/2013/04/24/10-myths-about-the-obamacare-medicaidexpansion/

Yelowitz, Aaron S. 1995. "The Medicaid Notch, Labor Supply and Welfare Participation: Evidence from Eligibility Expansions." Quarterly Journal of Economics 110 (4): 909-939.

Yelowitz. Aaron S. 1996. "Did Recent Medicaid Reforms Cause the Caseload Explosion in the Food Stamp Program?" UCLA Working Paper \#756.

Yelowitz, Aaron S. 2000. "Using the Medicare Buy-In Program to Estimate the Effect of Medicaid on SSI Participation," Economic Inquiry 38(3): 419-441. 


\begin{tabular}{|l|cccc|}
\hline \multicolumn{5}{|c|}{ Table 1: 2009 Earnings } \\
& Control Mean & ITT & LATE & p-values \\
& $(1)$ & $(2)$ & $(3)$ & $(4)$ \\
\hline \hline \multirow{2}{*}{ Employment (Any Earnings) } & 0.547 & -0.0042 & -0.016 & 0.266 \\
& & $(0.0037)$ & $(0.014)$ & \\
Amount of Earnings & & & & \\
& & & -194.93 & 0.500 \\
& $(10227.3)$ & $(76.8)$ & $(289.0)$ & \\
Earnings above FPL & & & & \\
& 0.131 & -0.0032 & -0.012 & 0.219 \\
& & $(0.0026)$ & $(0.0099)$ & \\
\hline
\end{tabular}

Note: Earnings include wage earnings and self-employment earnings. FPL is defined using adjusted household size (see text for more details). Column (1) reports the control mean of the dependant variable and standard deviation for continuous outcomes (in parentheses). Column (2) reports coefficient (and standard error in parentheses) on LOTTERY from estimating equation (1) by OLS; column (3) reports coefficient (and standard error in parentheses) on MEDICAID from estimating equation (2) by IV. Column (4) reports the p-values. All regressions control for dummies for number of household members on the lottery list and the 2007 value of the dependent variable. Standard errors are clustered by household. All regressions are weighted to adjust for a new lottery that started in late 2009. N=61790.

\begin{tabular}{|c|c|c|c|c|c|c|c|c|}
\hline \multicolumn{9}{|c|}{ Table 2: 2009 Benefits } \\
\hline & \multicolumn{4}{|c|}{ I. Any Receipt of Benefits } & \multicolumn{4}{|c|}{ II. Amount of Benefits Received } \\
\hline & $\begin{array}{c}\text { Control Mean } \\
\text { (1) }\end{array}$ & $\begin{array}{l}\text { ITT } \\
(2)\end{array}$ & $\begin{array}{l}\text { LATE } \\
\text { (3) }\end{array}$ & $\begin{array}{c}\text { p-values } \\
\text { (4) }\end{array}$ & $\begin{array}{c}\text { Control Mean } \\
(5)\end{array}$ & $\begin{array}{l}\text { ITT } \\
\text { (6) }\end{array}$ & $\begin{array}{l}\text { LATE } \\
\text { (7) }\end{array}$ & $\begin{array}{c}\text { p-values } \\
(8)\end{array}$ \\
\hline Food Stamps (SNAP) & 0.599 & $\begin{array}{c}0.025 \\
(0.0038)\end{array}$ & $\begin{array}{l}0.095 \\
(0.014)\end{array}$ & $<.001$ & $\begin{array}{c}1494.346 \\
(1893)\end{array}$ & $\begin{array}{c}72.75 \\
(15.75)\end{array}$ & $\begin{array}{l}276.19 \\
(58.85)\end{array}$ & $<.001$ \\
\hline TANF & 0.031 & $\begin{array}{c}0.0031 \\
(0.0015)\end{array}$ & $\begin{array}{c}0.012 \\
(0.0058)\end{array}$ & 0.042 & $\begin{array}{c}111.363 \\
(711)\end{array}$ & $\begin{array}{c}2.62 \\
(5.94)\end{array}$ & $\begin{array}{c}9.89 \\
(22.43)\end{array}$ & 0.659 \\
\hline SSI & 0.050 & $\begin{array}{l}-0.00024 \\
(0.0017)\end{array}$ & $\begin{array}{l}-0.00092 \\
(0.0065)\end{array}$ & 0.888 & $\begin{array}{c}30.626 \\
(137.972)\end{array}$ & $\begin{array}{c}0.25 \\
(1.08)\end{array}$ & $\begin{array}{c}0.93 \\
(4.09)\end{array}$ & 0.821 \\
\hline SSDI & 0.084 & $\begin{array}{c}0.0017 \\
(0.0014)\end{array}$ & $\begin{array}{c}0.0066 \\
(0.0054)\end{array}$ & 0.222 & $\begin{array}{c}943.189 \\
(3401.323)\end{array}$ & $\begin{array}{c}14.43 \\
(17.33)\end{array}$ & $\begin{array}{l}54.41 \\
(65.31)\end{array}$ & 0.405 \\
\hline
\end{tabular}

Note: All outcomes are measured at the individual level except for "Amount of TANF" and "Amount of SNAP" which are the amount that the individual's household received. Columns (1) \& (5) report the control mean of the dependant variable and standard deviation for continuous outcomes (in parentheses). Columns (2) and (6) reports coefficient (and standard error in parentheses) on LOTTERY from estimating equation (1) by OLS; columns (3) and (7) reports coefficient (and standard error in parentheses) on MEDICAID from estimating equation (2) by IV. Column (4) reports the p-values. All regressions control for dummies for number of household members on the lottery list and the 2007 value of the dependent variable. Standard errors are clustered by household. All regressions are weighted to adjust for a new lottery that started in late 2009. N=61790. 